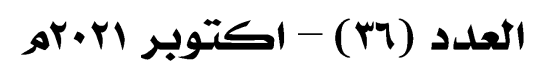

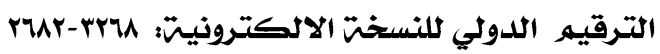

مجلت كليت التربيت - جامعت بورسعيد

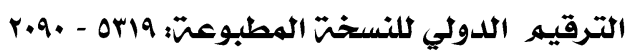

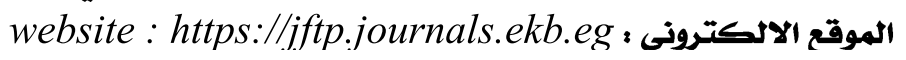

\title{
Back Translation of Literary Texts and Its Effectiveness in Developing Creative Writing Skills and Academic Self-Efficacy among English Department First-level Students
}

\author{
Dr. Maged Mohammedain
}

EFL Instructor and the director of the

Languages \& Translation Unit of the Public

Service Centre at Faculty of Education, Port

Said University

DOI: JFTP-2108-1155

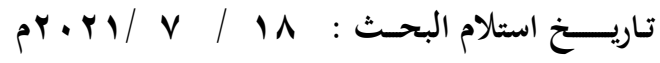

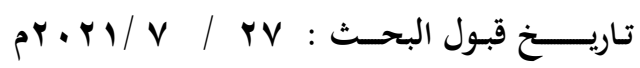

maged.mohamaden@edu.psu.edu.eg: البريد الالكتروني للباحث الجيث :

Faculty of Education Journal - Port Said University

Printed ISSN : 2090-5319
V0I. (36) - October 2021

On Line ISSN : 2682-3268

website : https://jftp.journals.ekb.eg/ 
Back Translation of Literary Texts and Its Effectiveness in Developing Creative Writing Skills and Academic Self-Efficacy among English Department First-level Students Dr. Maged Mohammedain

\section{ABS'TRAC'}

Varied strategies are proposed for the development of creative writing skills and academic self-efficacy among EFL students. Translation use, although pedagogically effective and educationally desirable, has been frequently ignored. The aim of this study was to investigate the effectiveness of a proposed unit based on the back translation strategy to develop creative writing skills and academic self-efficacy among English Department first-level students at Port Said Faculty of Education. (43) participants contributed to this experimental study of one-group design, conducted in the second semester of the academic year 2018/2019. A proposed unit based on the back translation strategy was designed to train the participating sample on translating multiple literary texts such as poems, short stories and songs. Additionally, a test on participants' creative writing skills as well as a scale on participants academic self-efficacy, both prepared by the researcher, were used as instruments to collect data. Later, sets of data were statistically analyzed using different statistical techniques. The results of the analyses revealed that the proposed unit based on the back translation helped to develop creative writing skills and academic selfefficacy among English Department first-level students. Implications, suggestions for further research, and recommendations for curricula and policy makers are included.

\section{KEYWORDS:}

EFL Students, Creative Writing, Back Translation Strategy, Academic Self-Efficacy 
Back Translation of Literary Texts and Its Effectiveness in Developing Creative Writing Skills and Academic Self-Efficacy among English Department First-level Students Dr. Maged Mohammedain

الترجمة العكسية للنصوص الأدبية وأثرها في تنمية مهارات الكتابة الإبداعية وفاعلية الذات الأكاديمية لادي طلاب المستوي الأول بقسم اللغة الإنجليزية

\section{unily}

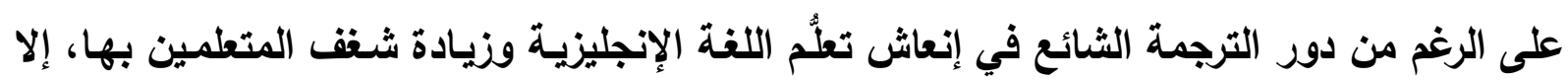

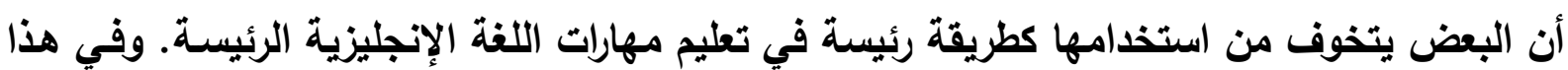

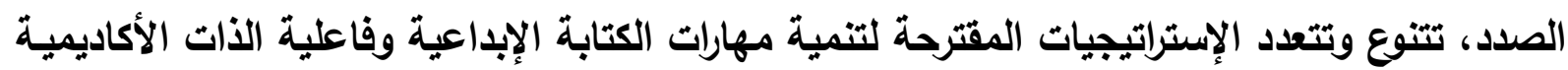

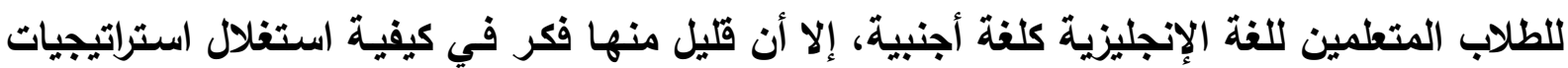
الترجمة في هذا السياق. وقد هدفت هذه الدراسة الي تعرف أثر استخدام وحدة تدريبية مقترحة قائمسة

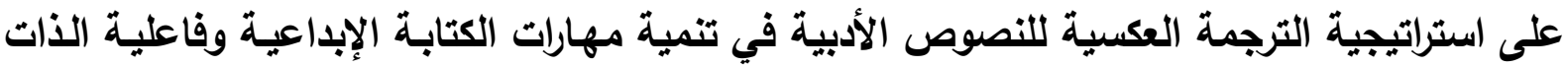

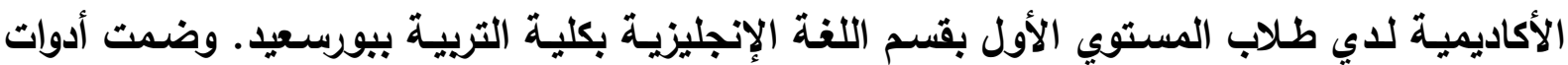

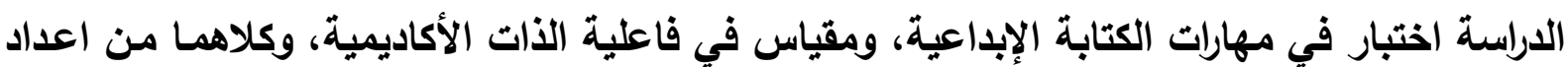

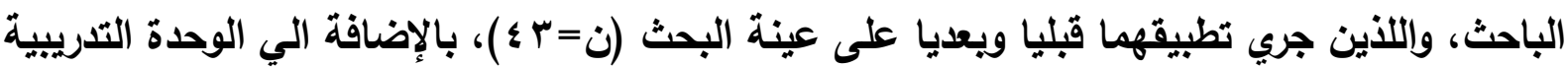

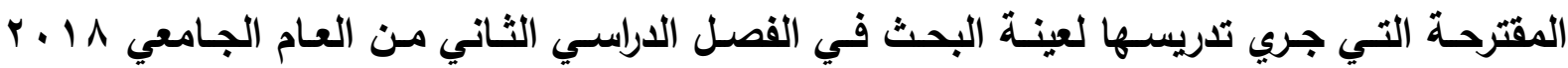

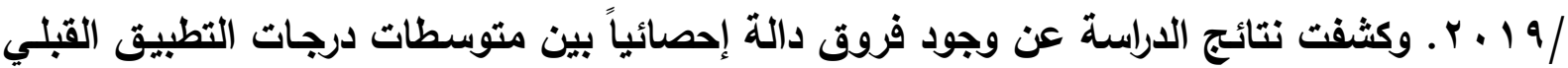

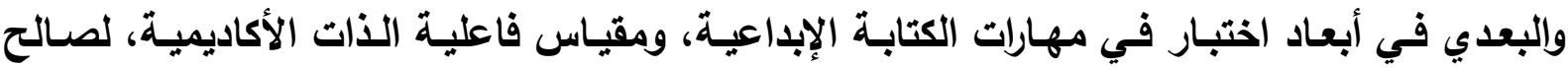

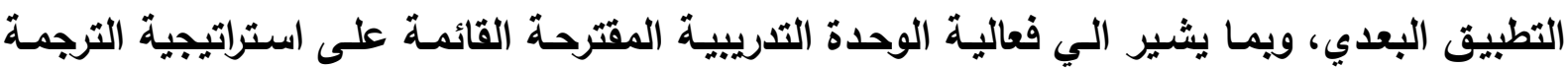

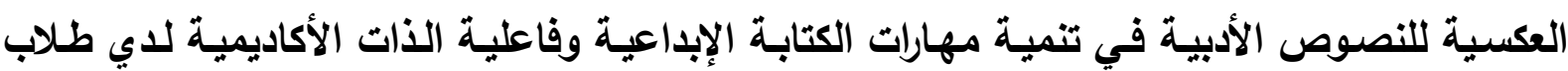

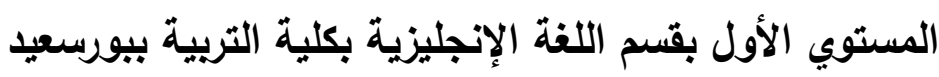

الكلمات الافتاحية المتية

الترجمة العكسية، الكتابة الإبداعية، فاعلية الذات الأكاديمية، الطلاب المعلمين للغة الإنجليزية. 
Back Translation of Literary Texts and Its Effectiveness in Developing Creative Writing Skills and Academic Self-Efficacy among English Department First-level Students

Dr. Maged Mohammedain

\subsection{Introduction}

Writing development, without any doubt, is critical to EFL students. Actually, writing offers EFL students plentiful opportunities to encourage reading, activate memory, organize ideas, express inner thoughts, increase level of confidence, reinforce grammar and vocabulary, and improve communication (Warren, 2013; Maley, 2012; Sternberg, et al., 2009). For that reason, one of the main goals of EFL teaching is to prepare students to write well.

Writing skills, as a matter of fact, include all the abilities related to generate, express and communicate clear ideas in an understandable readable form. Directly associated with writing skills, "creative writing skills" is a term commonly used to refer to one's capacity to use his/her own imagination and innovation in writing productive texts, showing expressiveness and originality rather than truthfulness (e.g., Maley, 2012; Honda, 2011). EFL students are involved in this type of creative writing when required to write literary texts taking the form of novels, poems, prose, short stories, songs and plays (Warren, 2013; Maley, 2009; Cremin, 2006). Several creative writing skills had been revealed in related literature. According to Maley (2009), creative writings have aesthetic and personal purposes, seeking to express the inner feelings of the writer, not facts. Cremin (2006: 415-433) indicated that the common features of creative writings are: (1) originality: the ability to generate inventive and original ideas, (2) intuition: the writer's inner sense guiding his steps during the writing process, (3) imagination: the writer's ability to assemble familiar ideas in the written text in an unfamiliar way, and (4) utilizing one's personal memories rather than facts.

A great deal of related research has pointed out the significance of having a good command of creative writing skills. For instance, the study of Sternberg, et al. (2009) indicated that creative writing gives EFL learners the opportunity to behave creatively and freely in their lives and to come up with possible and right alternatives. Additionally, Everett (2005) indicated that acquiring creative writing skills does not only improve writing and broaden imagination, but also provides EFL learners alternative ways to develop reading and distinctive writing styles. Furthermore, Harmer (2004) considered creative writing skills as a healthy way to overcome negative emotions and thoughts, and motivate students to make benefit of their linguistic capabilities. In the same vein, past research indicated that limited creative writing skills can negatively effect on overall writing quality (e.g., Neupane, 2014; Morley, 2007).

In this regard, writing and translation use, without any doubt, are deeply interconnected. At the heart of translation lies the ability to write well and use a clear and simple writing style in order to transmit all of the included 
Back Translation of Literary Texts and Its Effectiveness in Developing Creative Writing Skills and Academic Self-Efficacy among English Department First-level Students

Dr. Maged Mohammedain

facts, tone, message and intent of the original text writer in an understandable and acceptable form. As held by Perteghella \& Loffredo (2007), translation is a conscious process through which a massage is reconstructed and recreated in a target language according to its original massage.

A growing number of related researches indicated the type of writing made by of EFL learners in translation tasks is a "creative" one (e.g., Prasteyo, 2016; Khanmohammad \& Kehtari, 2015; Maley, 2012; Abasi \& Shabani, 2011; Gnecchi, et al., 2011). In a clear sense, the main role of EFL learners in translation tasks is to rewrite creatively in order to communicate the original author's ideas in a different language using a proper way. They do not translate the source text identically. Like creative writers, they follow specific rules to produce a target text in a way that is new, innovative and unique. They have to make a full understanding of the source text. They have to keep sentences brief, avoiding the use of too vague, exaggerated, and sophisticated words. Furthermore, they have to draft and revise the target text as many times as needed to produce an accurate and culturally acceptable text. For example, the study of Gnecchi, et al. (2011) concluded that for the case of humor translation, translators' innovative and creative decisions lead to accurate translations. According to Abasi \& Shabani (2011:523), translation is impossible without the "creative voice" of the translator who should possess an artistic sensibility and intuition more than a dedication to traditional translation rules.

Interest in the role of translation in the development of writing skills, including creative writing ones, is increasing day by day in EFL relevant research (e.g., O'Brien, 2013; Dam-Jensen \& Heine, 2013; Cho, 2006). Conventionally, translation is a mental activity in which a translator is often faced with a rewriting task that requiring to deal with and engage in two entirely different languages. For the text to be translated accurately, creativity is required on the part of the translators to make a conscious effort to retain the original meaning or message and present a creative equivalent one within the target context. Added to this, translation tasks, seemingly, play an effective role in the development of creative writing because a big part of translators' job is to think outside of the box to realize, identify, incorporate, take in, and simplify information mentioned in the original text.

Like its role in the development of creativity in writing, the role of translation in the development of EFL students' academic self-efficacy is an issue for permanent discussion in relevant research (e.g., Haro-Soler, 2017; Genç, et al., 2016; Liu, 2013; Hosseini Fatemi \& Vahidnia, 2013). Becoming a successful translator overlaps with varied personality traits, including academic self-efficacy, linguistic expertise, attention to details, and passion 
Back Translation of Literary Texts and Its Effectiveness in Developing Creative Writing Skills and Academic Self-Efficacy among English Department First-level Students

Dr. Maged Mohammedain

for language learning. Translation tasks encourage EFL students to look at effective ways in order to overcome difficulties and challenges of the source text and to keep intrinsically interested and involved in the translation tasks they practice (Atkinson, 2012; Muñoz, 2014). Moreover, in relevant research, translators' academic self-efficacy has been found to positively correlate with some translation related aspects, including job satisfaction (Atkinson, 2012), reading comprehension (Bolaños-Medina, 2014), the ability to apply some risk-taking strategies (Haro-Soler, 2017), and the ability to justify decisions (Way, 2016).

Several strategies had been proposed in related literature to improve EFL students' creative writing skills such as reading aloud, regular exercises, and a writing tutor's guidance. Translation use, although pedagogically effective and educationally desirable, has been frequently ignored in this context.

The back translation strategy is one the of possible strategies proposed in related literature to satisfy the need to develop translators' creative writing and academic self-efficacy (e.g., Behr, 2016, 2017; Vu Cong, et al., 2018; Bernadine, 2016; Wang, 2009; Baker, 2002). As its name suggests, back translation strategy requires an EFL learner, who does not have access to the source text before, to retranslate (rewrite) a translated text back into its source language. Later, students' translations are compared with the original text. Back translation can be performed for most types of creative writing tasks including literature, prose, poetry, and magazines to give an accurate depiction of the exact meaning. According to Bernadine (2016), the use of back translation strategy is beneficial to EFL learners because it provides them a deeper insight into the rendition of materials at hand; facilitate understanding of the differences between both the source and target languages; and suggest broader recommendations for language acquisition. Achieving success in using the back translation strategy in translation tasks depends on EFL learners' general understanding of the text, linguistic capabilities, socio-cultural awareness, and abilities of imagination and creativity (Wang, 2009; HE, 2002). Hence, back translation strategy could be a useful tool to develop creative writing and increase self-efficacy as it helps translators identify and overcome challenges and obstacles of the source text.

As mentioned above, back translation strategy has drawn a growing attention as an effective strategy for the development of language skills and personal traits of EFL learners. Yet, to the researcher's best knowledge, no close empirical studies in Egypt have investigated its effect on the development of students' creative writing skills and academic self-efficacy in a single controlled study. Seeking to bridge this gap, the present study focused on the effectiveness of a proposed unit based on the back 
Back Translation of Literary Texts and Its Effectiveness in Developing Creative Writing Skills and Academic Self-Efficacy among English Department First-level Students

Dr. Maged Mohammedain

translation strategy to develop creative writing skills and academic selfefficacy among English Department First-level.

\subsection{Context of the Problem}

Translation use and creative writing are deeply interconnected. Translation is a type of rewriting in which translators use his own creativity to produce the target text in an understandable inventive way. Whether in translation or creative writing tasks, EFL student are required to see below the surface and think out of the box (e.g., Rahemi, et al., 2013; Akbari, 2007; Aksoy, 2001).

Nevertheless, this indisputable interconnected relationship between translation use and creative writing does not receive as much attention as it would deserve. This finding had been derived from the researcher's own observations and experience as a language instructor in addition to his position as the director of the Languages \& Translation Unit of the Public Service Centre at Port Said Faculty of Education. One of the main objectives of the EFL courses for EFL first-level students is to help students write and think through topics that give voice to their inner creativity, innovations and thoughts. However, a very common problem in the EFL context at Port Said Faculty of education was that students were hesitated to engage in creative writing tasks such as prose, poems, fiction, songs or even short stories, which are rich with aesthetic and self- expressive sentences. They appeared struggled with the choice of suitable wording or expressions, and with capturing the meanings, rhyme and specific expressions. They were unable to communicate their thoughts or message effectively. They were less confident in their own academic abilities to write the target texts without mistakes. Because of this, they tended to avoid these creative writing tasks, have low levels of commitment, and give up quickly.

To survey this problem, the researcher conducted semi-structured interviews with a sample of (9) participants of the English department firstlevel students at Port Said Faculty of Education to explore their views and perceptions. These interviews communicated to the researcher their frustration and worry about their creative writing experiences. Most of them expressed their lack of confidence, sharing a belief that that grammatically correct writings are only accepted. Most of them expressed their displeasure to such creative writing tasks as requiring them to produce the idea in a new and inventive way to be accepted. Some of them expressed dissatisfaction with the instructor as focusing on surface errors regarding grammatical structure, spelling and punctuation; and giving no feedback to their creative ideas themselves. Some admitted their translation errors are due to lack of sufficient knowledge of how to write the target text in a powerful style. It was evident that they lack adequate training of 
Back Translation of Literary Texts and Its Effectiveness in Developing Creative Writing Skills and Academic Self-Efficacy among English Department First-level Students

Dr. Maged Mohammedain

creative writing skills, and this lack has affected negatively their academic self-efficacy.

With this in mind, it was still unclear what strategy to be utilized. Reviewing related literature (e.g., Vu Cong, et al., 2018; Bernadine, 2016; Colina, et al., 2016; Akhiroh, 2013; Harkness, et al., 2009; Paegelow, 2008; Douglas and Craig, 2007), translation use was found desirable to develop creative writing. The back translation is a common translation used strategy, little studied, that is considered as a highly useful device in developing the abilities of translators and assessing the quality of their writings. Back translation strategy depends on meaningful activities, uses rich authentic texts to translate, encourages students to write and rewrite for correctness, and provide effective feedback to students by comparing the retranslated text to the original text (Behr, 2016; Racoma, 2016; Ozolins, 2009), leading to higher levels of translating abilities, academic self-efficacy and motivation.

Inspired by this scarcity of such a research in the Arab area, the present study focused on the effectiveness of a proposed unit based on back translation of literary texts in order to develop creative writing skills and academic self-efficacy among English Department First-level students at Port Said Faculty of Education.

\subsection{Statement of the Research Problem}

English department first-level students at Port Said Faculty of Education suffered from weaknesses in their creative writing skills, represented in their inability to engage in creative writing texts such as prose, poems, fiction, songs or even short stories full of aesthetic and self- expressive sentences; and the production of low-quality target texts, negatively affecting their academic self-efficacy. These aspects of weaknesses were attributed to limited training of translation of creative literary writings. Then, in the present study, the researcher built a proposed unit based upon the back translation strategy, offering plentiful opportunities to retranslate literary texts back into its source language, and investigated its effectiveness on the development of their creative writing skills as well as their academic self-efficacy.

\subsection{Research Questions}

To address the aforementioned research problem, the main question the present study attempted to address was: "What is the effectiveness of a proposed unit based upon the back translation strategy on the development of creative writing skills and academic self-efficacy among English department first-level students at Port Said Faculty of Education?". With this in mind, the present study was designed to address the following research questions: 
Back Translation of Literary Texts and Its Effectiveness in Developing Creative Writing Skills and Academic Self-Efficacy among English Department First-level Students

Dr. Maged Mohammedain

1. What is back translation strategy?

2. What is academic self-efficacy?

3. What are creative writing skills necessary for the English department first-level students at Port Said Faculty of Education?

4. What are the specifications of the proposed unit based upon the back translation strategy?

5. What is the effect of the proposed unit on the development of creative writing skills of the English department first-level students at Port Said Faculty of Education?

6. What is the effect of the proposed unit on the development of academic self-efficacy in translation of the English department first-level students at Port Said Faculty of Education?

\subsection{Objectives}

The main aim of this study was to investigate whether the use of the proposed unit based on the back translation strategy could develop creative writing skills and academic self-efficacy of the English department firstlevel students at Port Said Faculty of Education. To achieve this ultimate aim, this study was endeavored to achieve the following objectives:

a. To highlight what the back translation strategy is, what creative writing skills are, and how the English department first-level students at Port Said Faculty of Education can successfully acquire to improve their academic self-efficacy.

b. To shed light on the significance of developing academic self-efficacy in writing and translation tasks in the EFL learning environment to meet the increasing needs for competent learners.

c. To adopt a new methodology for writing and translation instruction, representing a rich and varied language experience, and helpful for EFL teachers to motivate EFL students write and translate creatively and show higher levels of academic self-efficacy and commitment.

d. To provide a concrete experiment helpful for empirical research concerning the validation of the back translation strategy.

e. To help the English department first-level students at Port Said Faculty of Education develop and foster their creative writing skills and academic self-efficacy through translation tasks that give a voice to their inner creativity.

\subsection{Significance}

The above-mentioned expected outcomes of this study may contribute:

1- To provide EFL instructors at the university level with a helpful methodology to overcome frequent writing or translation problems. 
Back Translation of Literary Texts and Its Effectiveness in Developing Creative Writing Skills and Academic Self-Efficacy among English Department First-level Students

Dr. Maged Mohammedain

2- To EFL students develop their creativity and produce writings and translations effectively and accurately by adopting a strategy that provides feedback and promotes deeper level of EFL learning.

3- To provide theoretical and pedagogical implications for translation and writing researchers, teachers, students and curriculum designers interested in writing and translation learning and the factors affecting their correctness and accurateness.

4- To help EFL researchers have better understanding of the significance of creative writing skills and academic self-efficacy in translation in producing target texts full of faithfulness and expressiveness.

5- To urge university curricula designers and developers to integrate valuable techniques used by competent translators in writing various genres and topics.

\subsection{Procedural Definitions of Terms:}

- Creative writing: a self-expressive form of writing in which EFL students search for meanings to express accurately their ideas and thoughts in a free imaginative way. Types of creative writing include poetry, novels, short stories, and personal essays.

- Creative Writing skills: the ability to communicate ideas, thoughts, and arguments smoothly and correctly in the target text.

- Back translation: a strategy includes, without access to the original text, taking a translated version of a certain text, retranslating it back into its original language, and then comparing the resulted translation with the original text.

- Academic self-efficacy: an individual's belief in his or her capacity to produce error-free, understandable and acceptable texts.

- The source language: the language being translated from.

- The target language: the language being translated into.

\section{Review of Literature}

In this part, some background information on translation use in the EFL environment, the back translation strategy, creativity in translation, creative writing skills, academic self-efficacy, is reviewed below.

\subsection{Translation Use in the EFL Environment}

Translation use in the EFL environment is a controversial topic among English language teaching researchers. For long centuries, translation use as an instructional tool had been prevalent in the EFL Environment till the predominance of the communicative method in language teaching. Although translation use was regarded as an obstacle to EFL students' acquiring $L 2$ and expressing themselves freely in the new language, translation refused to disappear totally from the language classroom (Zhao, 2015; Mogahed, 2011; Leonardi, 2011). 
Back Translation of Literary Texts and Its Effectiveness in Developing Creative Writing Skills and Academic Self-Efficacy among English Department First-level Students

Dr. Maged Mohammedain

In relevant research, a great deal of researchers such as Ghaiyoomian \& Zarei (2015), Mahboob and Elyas (2014), Karimian and Talebinejad (2013), and Machida (2011), advocate the use of translation, indicating that excluding translation use as an educational tool entirely form the EFL Environment leaves teachers and students feeling uncomfortable. The findings of their studies provided numerous benefits of translation use. For instance, Ghaiyoomian \& Zarei (2015) advocated translation use in the EFL environment for its effect on reducing students' confusion and misunderstanding of grammar constructs. Machida (2011:743), also, indicated that translation use "provides plentiful opportunities for the learners to pay attention to the relationships between form and meaning.". Further, Mahboob and Elyas (2014) advocated the use of translation tasks in developing students' comprehension of the contextual meaning, in order to produce correct English sentences.

Seemingly, this ongoing debate about the status of translation use as an educational strategy in the EFL environment is confined to academic circles. Recent developments in the domains of global communication, business, transport, and new technologies (especially the Internet) led to a progressive change towards the significance of translation use and its required role. For that reason, there is mutual agreement among researchers that some EFL learners need to use translation. For instance, Zawawy (2008) considered translation as the 5th language skill to be taught and practiced. Translation is there in every situation. Day-to-day life requires translation. Messages and information from one language to another information cannot be successfully transferred worldwide without the use of translation. Thus, translation use and the ability to translate accurately and in an understandable form, the researcher believes, has become vital and highly demanded for EFL students' alongside with the four language skills: reading, writing, speaking, and listening.

\subsection{The Use of the Back Translation Strategy}

Traditionally, a strategy is an array of planned, goal-oriented, and sequenced procedures which can be monitored and modified. Translation strategies are used in tasks to find adequate equivalences that can convey the same message or meanings of the targeted text. As held by Ozolins, (2009), using a translation strategy is necessary to detect a problem exists while conveying the message and meanings of a text. According to Cook (2010), general characteristics of a successful translation strategy includes: systematic and hierarchical, goal-oriented, problem-centered, to be textually manipulated, to be empirical and applied in varied contexts, to be applied consciously.

With this in mind, the back translation strategy is one of the prominent translation strategies that had been suggested in related literature, seen 
Back Translation of Literary Texts and Its Effectiveness in Developing Creative Writing Skills and Academic Self-Efficacy among English Department First-level Students

Dr. Maged Mohammedain

from different perspectives. In related literature, (the back translation strategy) is a term widely used by scholars and professional translators to describe a process of translating a text, which has been previously translated, back to its source language. A definition of the back translation strategy was mentioned by Harkness, et al. (2009), in which the back translation strategy is to translate back a translated text into its original language. Further, Behr (2017) defines the back translation strategy as the re-translation of a translated text back into the original language in addition to the subsequent comparison of the original version and the back translation.

According to Racoma (2016), the back translation is a systematic and a hierarchical strategy, happening in three steps, as depicted in Figure (2.1):

(i) to retranslate a translated text back into the original language.

(ii) to compare the new translation with the original text in terms of message and effect, and

(iii) to reconcile meaningful variations between the two translations.

Added to this, the back translation is a goal-oriented strategy. This strategy is used for achieving varied objectives. According to Douglas \& Craig (2007), the goal of the back translation strategy is to check for variations in translation quality between the new translation and the original one, in terms of certain elements such as the meanings, message, and effect. In addition, Ozolins (2009) held a belief that the goal of the back translation strategy is to ensure that the new and the original texts are accurate and similar as much as possible, particularly while dealing with sensitive materials such as reports and surveys. Moreover, Khosravani \& Vahid Dastjerdi (2013) asserted that the back translation strategy achieves two purposes: (i) to show the structural and conceptual differences between the original and the target languages in translation, and (ii) to familiarize translators for varied situations in the target language.

Figure (2.1): Steps of the Back Translation Strategy (Source: https://www.pactranz.com/back-translation)

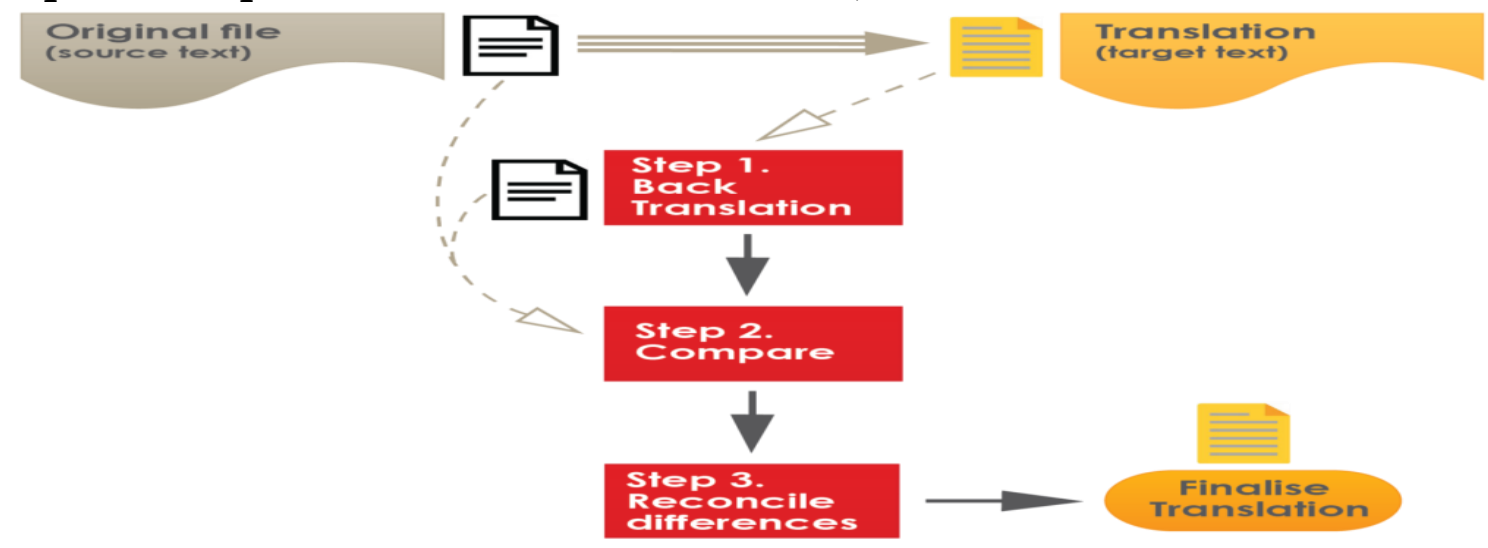


Back Translation of Literary Texts and Its Effectiveness in Developing Creative Writing Skills and Academic Self-Efficacy among English Department First-level Students

Dr. Maged Mohammedain

Further, the back translation is a problem- centered strategy. It helps translators see obstacles or errors found in their translations, and recognize their consequences on the overall quality and readers' understanding. Behr (2017) indicated back translation is preferably used when EFL learners are not familiar with the source language. Khosravani \& Vahid Dastjerdi (2013) indicated back translation is critical to overcome the difficulties arising from lack of equivalences among languages.

The back translation strategy, as any other strategies used, has pros and cons that should be considered. In related literature, some researchers advocated that the back translation strategy can fulfill the needs of its users in a way that's better than other translation strategies can do for you. According to Bernadine (2016), the back translation makes it easy to focus on errors, ambiguities or confusion that may appear. It also helps translators increase their translation's credibility and accuracy. ensure the highest quality of all translated materials used for this purpose. Behr (2016) indicated the back translation strategy helps its users to grasp the precise meanings and easily identify the differences between the two translations, giving them a big control of the content of the translation. According to Douglas \& Craig (2007), the back translation produces successful translated texts and ensures the target text is culturally accurate as well, particularly in terms of idioms and colloquial language used in the text. Khosravani \& Vahid Dastjerdi (2013) sees the back translation as a useful strategy, because $90 \%$ of the sentences could be tested, leading to a better translation.

Alongside the above-mentioned advantages of the back translation strategy, some researchers pointed out some shortcomings in this strategy. A negative aspect of the back translation strategy was held by the study of Douglas and Craig (2007) which indicated the back translation cannot be helpful when the equivalent of a word does not exist in the target culture, and, therefore, may be somewhat misleading. Another negative aspect was given by Ozolins (2009) who demonstrated that the back translation strategy does not detect all errors in the target text itself. Also, Khosravani \& Vahid Dastjerdi (2013) pointed out two limitations of the back translation strategy: (i) reproduction of the original meaning does not address directly the meaningfulness of the material in the target language, (2) translations that retain grammatical forms of the original language may not be meaningful. Anyway, regardless of these limitations, the back translation strategy still witnesses a widespread popularity in the translation field. 
Back Translation of Literary Texts and Its Effectiveness in Developing Creative Writing Skills and Academic Self-Efficacy among English Department First-level Students

Dr. Maged Mohammedain

\subsection{Creativity in Translation Tasks}

Creativity, in general, is one's imagination to generate novel ideas, to make unnormal connections between things, or come up with alternatives possibilities in order to solve problems or to communicate with others. The main qualities of creativity derived in related research are originality, extraordinariness, exceptionality, composing things in innovative and imaginative ways (e.g., Chen \& Zhou, 2010; Chesterman, 2009; Brockbank, 2001).

With concern to translation, related research indicated translation and creativity are inseparable (e.g., Perteghella \& Loffredo, 2007; Boase-Beier, 2007; Bassnett, 2004). In a clear sense, the source text includes the author's self-expression of his thoughts and personality. The translator' job is to write the best translation of the same text to people who do not speak and write the original language. Meanwhile, the translator is required to maintain the message and intent of the source text. To achieve these desirable outcomes, the translator has to make use of his creativity to avoid the production of a target text that is inaccurate in intent or tone. Perteghella and Loffredo (2007:10) pointed out that both writer and translator are equally constrained as the role of both is to handle and craft a raw material of language aqnd come up with a novel one. If the translator lacks creativity, the target text will be unable to live up to the source one. In addition, Bassnett (2004: 69), assured that translators need to possess "creative genius" to produce accurate translations.

In translation, as Boase-Beier (2007:55) suggested, the term "creativity" is used to refer to literary texts, while technical or legal texts are factual ones. Related literature found translating literary texts constitutes a huge problem for translators because they are culturally bound, as their creative content and writing styles are affected by with the source culture. Translator's own creativity is the right key to help the translator capture the meanings and intent of literary text, and produce equivalent aspects (Dam-Jensen, \& Heine, 2013; Abasi \& Shabani, 2011; Akbari, 2007). According to Dam-Jensen, \& Heine (2013), mastery of both the source and target languages as well as their associated cultures are the main factors affecting successful use of creativity in translation. Mastery of both the source and target languages is significant to ensure that the translator communicates every aspect of the content and the meaning conveyed by the source text accurately and clearly. If the translator lacks mastery of both the source and target languages, his translation will be deemed week and poor. In addition, having a good command of the cultures associated helps the translator choose the closest equivalent vocabulary and facilitate understanding of the translated text. 
Back Translation of Literary Texts and Its Effectiveness in Developing Creative Writing Skills and Academic Self-Efficacy among English Department First-level Students

Dr. Maged Mohammedain

\subsection{Creative Writing Skills}

Directly associated with creativity, creative writing is any form of writing which is written to simply express one's ideas and opinions thoughts, experiences or emotions. Being able to write creatively is one of the most important qualities that an EFL learner should acquire throughout his or her university education years. Writing scholars have different perceptions of what creative writing is. For instance, according to Chen \& Zhou (2010), creative writing is an open-ended process that builds on creativity and is relevant to the development of students' thinking skills. According to Morley (2009), creative writing is the production of fictional narratives (non-documentary, non-academic). According to Bennett, et al., (2008: 2), "creative writing is the study of writing (including poetry, fiction, drama, and creative non-fiction) and its contexts through a creative and reflective process". As held by Maley (2003), creative writing is to invest one's imagination freely to put ideas and feelings about a particular topic on a paper. According to Cremin (2006), creative writing is any type of writing, fiction or non-fiction.

It is evident from the aforementioned definitions that creative writing is revolving around human experiences, going beyond the ordinary and producing something unique, novel and new to others. Generally, the present researcher believes that creative writing is a self-expressive form of writing done to express personal perspectives, feelings, emotions or thoughts using a non-academic or non-technical style to enable the audience understand the writer's purpose or message. It requires a lot of time, creativity and imagination.

Types of creative writing include varied forms aiming to share a human experience such as poems, novels, short stories, songs and personal essays (Hyland, 2003; Harmer, 2004). According to Hyland (2003:229), types of creative writing include novels, short stories, poems, screenwriting and playwriting. Improving at practicing creative writing tasks requires EFL students to possess many skills. In related literature, many skills thought to be involved in creative writing. For example, Baptiste et al., (2012) divided creative writing skills into six broad categories. Each domain involves many sub-skills, as follow:

i. Skills related to general knowledge: Verbal intelligence; Working memory; Topic knowledge; Knowledge on the writing process itself; Cognitive flexibility; Being able to integrate or synthesize the existent knowledge into a coherent composition; Observation; and Visualization

ii. Skills related to creative cognition: Originality or the ability to generate unique ideas; Selective combination of the elements of a problem to creatively solve; Associative thinking to associate ideas 
Back Translation of Literary Texts and Its Effectiveness in Developing Creative Writing Skills and Academic Self-Efficacy among English Department First-level Students

Dr. Maged Mohammedain

with each other; Divergent thinking to produce a wide range of ideas; and Generative thinking.

iii. Skills related to executive functioning: Planning and organizing ideas; the ability to sequence ideas; and Concentration to manage the writing environment or deal with its constraints.

iv. Skills related to motivation: Extrinsic motivation to help students get through difficult writing assignments; intention to monitor and direct actions; Setting intended outcomes; and Risk taking to deal with ambiguous situations;

v. Linguistic and literary Skills: the ability to build sentence structures and construct meaning using context; elaboration; the ability to describe in order to arouse readers' visualization and imagination; vocabulary; knowledge of the organizing structures of language that support meaningful text, effective introduction of the problem; and reading comprehension.

vi. Psychomotor Skills: handwriting, revising, generating new ideas, mastery of spelling.

Moreover, Everett (2005) argued that in creative writing tasks, EFL students are given space to write the content freely and creatively; therefore, imagination and originality are the main skills to be involved in creative writing more than the standardization of thought and truthfulness. Anae (2014) indicated that planning, organization and discovery of thought are the key skills EFL students need to deal with daily creative writing tasks successfully. Additionally, Honda (2011) considered fluency, flexibility, originality and elaboration as the essential skills of creative writing.

The aforementioned creative writing skills help EFL students, as indicated by the findings of previous research, get definitive benefits in many respects, as follow:

a. they help them investigate and grasp the functions and value of the writing process, leading to an improvement in their skills of reading and writing (e.g., Shanahan, 2006).

b. they help them learn how to approach life in a creative way (e.g., Sternberg, et al., 2009).

c. They boost future imaginative thinking in EFL students, and enrich the learning environment (e.g., Runco, 2009).

d. They boost motivation, self-confidence and self-esteem in EFL students, and promote their personal and linguistic growth (e.g., Maley, 2009).

e. Creative writing paves the way for students' innovation, giving them an opportunity to say something new, unique and original (e.g., Spiro, 2004). 
Back Translation of Literary Texts and Its Effectiveness in Developing Creative Writing Skills and Academic Self-Efficacy among English Department First-level Students

Dr. Maged Mohammedain

For the purposes of the present study, Maley (2012) urged EFL teachers to implement the following considerations in the EFL instruction environment to help EFL students develop their creative writing skills:

- To create a pleasant atmosphere.

- To promote the development of group cohesiveness.

- To Increase the students' expectancy of success in particular tasks.

- To make learning more stimulating and enjoyable.

- To increase the attractiveness of creative learning tasks.

- To make learning enjoyable for the learners.

- To present and administer tasks in a motivating way.

- To build learners' confidence by providing regular encouragement.

- To increase student motivation, autonomy and cooperation with others.

- To offer feedback in a motivational manner

As can be seen from the above-mentioned findings of previous research, creative writing is a way of expressing one's ideas, feelings, experience and thoughts. Creative writing skills provides EFL students with a big chance of succeeding in the EFL environment. Hence, it becomes vital for EFL teachers to pay concentration on the development of creative writing skills of the EFL students. This study was established with an aim of developing creative writing skills among English Department First-level students at Port Said Faculty of Education.

\subsection{Academic Self-Efficacy}

Recent research indicated that it is important to take into account different learning styles and individual characters of EFL learners, believed to play a significant role in EFL instruction success. Broadly speaking, the term "self-efficacy", first coined by Albert Bandura (1977), is a term used to refer to a set of individual's beliefs in his or her own capacity to organize and carry out a sequence of actions required to achieve an intended outcome (Dündar, 2015; DeTure, 2004). Perceived self-efficacy is significant to successfully solve a task, and to carry out a learning activity. High or low self-efficacy depends on many factors, such as resilience to stress, dynamic interactions within groups, and improved academic performance.

Rooted in Bandura's self-efficacy theory, the term "academic selfefficacy" describes one's cognitive, social and emotional engagement in the learning environment. It is strongly related to the competition among learners for success in the academic fields. Graham, (2011) defined it as students' judgements of their competence to accomplish their assigned classwork. Bandura (1993) suggested some or all of the following characteristics to students with high academic self-efficacy:

- see problems as challenges to be taken on and met, 
Back Translation of Literary Texts and Its Effectiveness in Developing Creative Writing Skills and Academic Self-Efficacy among English Department First-level Students

Dr. Maged Mohammedain

- goal-oriented and committed to their own academic goals,

- task-diagnostic oriented, and

- consider insufficient effort or knowledge as the main reason of failures.

As depicted in the figure below, academic self-efficacy is influenced by four sources: (i) mastery experience (one's own experience), (ii) vicarious experiences (other people's experience), (iii) verbal persuasion (appraisal or feedback from others), and (iv) affective states (i.e., stress, mood, and fatigue) (Kargar \& Zamanian, 2014; Hossesini, et al., 2013; DeTure, 2004).

Figure (2.2): Sources of academic self-efficacy (Source: Sharma \& Nasa, 2014)

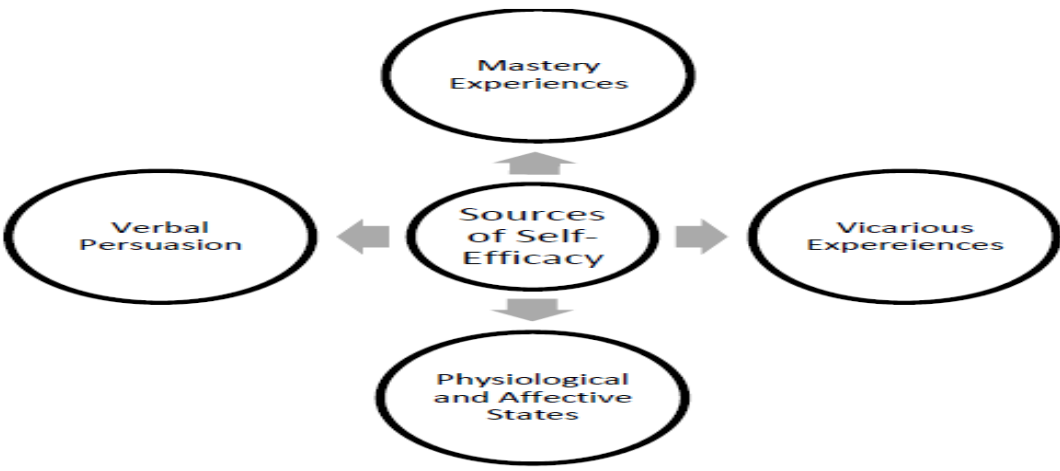

In related literature, academic self-efficacy has been found to influence students' academic achievement (e.g., Yilmaz, 2010), motivation and cognition (e.g., Raoofi, et al., 2012), the development of listening (e.g., Graham, 2011), improvement of speaking (e.g., Liu, 2013), enhancement of writing and reading skills (e.g., Kargar \& Zamanian, 2014). In this regard, Sharma \& Nasa (2014) proposed the following roles for teachers to develop academic self-efficacy:

- To get students acquainted with the educational goals to be mastered,

- To train students on effective strategies to improve their academic performance,

- Modeling cognitive strategies and self-regulatory techniques that provide remedy to students' cognitive and affective deficiencies.

- To provide regular, positive, adequate and immediate feedback in cases of their progress.

Commentary on Previous Research: Previous studies made it clear that Translation use and creative writing are interconnected, and that ignoring this indisputable interconnected relationship can seriously decrease students' levels of academic self-efficacy. Although varied strategies were proposed in related literature for the development of creative writing skills and academic self-efficacy among EFL students, most of previous research does not take translation strategies, such as the back translation strategy, into account. To train EFL students on writing creatively through 
Back Translation of Literary Texts and Its Effectiveness in Developing Creative Writing Skills and Academic Self-Efficacy among English Department First-level Students

Dr. Maged Mohammedain

translation activities is highly required because students' failing to retranslate (rewrite) a text, as in the back translation tasks, in a creative manner could seriously distort its meanings, message, and effect; and present the original text in an entirely different view. Based upon reviewing related literature, the present research was designed to investigate the effectiveness of a proposed unit based on the back translation strategy to develop creative writing skills and academic self-efficacy among English Department First-level students at Port Said Faculty of Education. All of the research are presented in the coming part.

\section{Methodology}

Based on the theoretical framework in section II, this section provides a detailed explanation of the research design, hypotheses, sampling, instruments, and procedures followed throughout the current study to address the research problem.

\subsection{Design}

Two methods have been employed in the present study. Firstly, a descriptive analytical method was used to identify, summarize and provide the researcher insight into the back translation strategy, creative writing skills, and academic self-efficacy. The second one was a one-group experimental design method, where all individuals are given the same treatments and assessments, in order to investigate whether the independent variable of this study (the proposed unit based on the back translation strategy) has / has not an impact on the dependent variables (creative writing skills, and academic self-efficacy in translation of students).

\subsection{Hypotheses}

This study attempted to verify the following research hypotheses:

1- There is a statistically significant difference at $(\alpha \leq 0.01)$ between the mean scores of the experimental group students in the pre-application and post- application of the four dimensions of the creative writing skills test, in favor of the post applications.

2 - There is a statistically significant difference at $(\alpha \leq 0.01)$ between the mean scores of the experimental group students in the pre-application and post- application of the four dimensions of the academic self-efficacy scale, in favor of the post applications.

\subsection{Sampling}

The participants contributed to this study were (43) EFL students enrolled in the first level of the English Department, in both the general and basic divisions, at Port Said faculty of education in the second semester of the academic year (2018-2019). All the participants were Arabic native speakers. They were given an overview of the research and informed that 
Back Translation of Literary Texts and Its Effectiveness in Developing Creative Writing Skills and Academic Self-Efficacy among English Department First-level Students

Dr. Maged Mohammedain

no extra points would be given for their participation. All of them received the proposed treatment. The one-group experimental design was necessary because of the researcher's limited time, and to maintain a large focus on the participating sample and ensuring that they were receiving the best possible learning experiences.

\subsection{Instruments}

The instruments used to carry out, obtain, and analyze the data of this study were;

1- A proposed unit based on the back translation strategy.

2- A test on participants' creative writing skills.

3- A scale on participants academic self-efficacy in translation.

All instruments were designed in the light of the findings of related research and the present research problem, aims and objectives. The test of participants' creative writing skills and the scale on participants academic self-efficacy were formulated and edited in the English language. Only the proposed unit based on the back translation strategy consisted on texts written in both English and Arabic. To make data collection easier, all of the above-mentioned instruments were prepared by the researcher himself and presented to the participating sample in a paper format.

Before the treatment, a pre- application of the test and the scale was conducted. Later, the proposed unit based on the back translation strategy was instructed as an extracurricular activity for the experimental group students. It took five weeks. In every week, students were receiving two sessions, each lasted for two hours, of creative writing training and completed different translation activities based on the back translation strategy. When completed, all students in the experimental group were given a post-test of creative writing skills and a post-scale of academic selfefficacy in translation, which both were the same as the pre- applications. Their results in the pre-applications and post- applications were compared to each other to check the progress of the participating sample.

\subsubsection{The Proposed Unit based upon the Back Translation Strategy.}

The proposed unit based on the back translation strategy was designed to cover significant areas in translation in addition to creative writing genres in a way that ensures providing the participating sample with the best EFL learning experiences that can sharpen their creative writing skills and increase their levels of academic self-efficacy. This design stood on objectives of the present study, the research population, and the findings of related research such as Akkaya (2014), Anae (2014), Warren (2013), DamJensen \& Heine (2013), Tyupa (2011), Larios, et al. (2011), Ozolins (2009), Paegelow (2008) and Perteghella \& Loffredo (2007). 
Back Translation of Literary Texts and Its Effectiveness in Developing Creative Writing Skills and Academic Self-Efficacy among English Department First-level Students

Dr. Maged Mohammedain

Appendix (B) presents a detailed explanation of the proposed unit design.

To ensure face and content validity, an expert panel including $(\wedge)$ experts in the fields of TEFL, Curricula \& Instruction, Linguistics and Educational Psychology reviewed the proposed unit based on the back translation strategy in terms of quality, preciseness, sequence, and potential to attain its intended objectives. The expert panel assured the overall suitableness and the relevancy of the proposed unit components. In order to capitalize the proposed unit outcomes, the following considerations were taken into account during instruction:

1- To balance the proposed unit objectives and EFL students' educational needs.

2- To review and recognize relevant and similar training programs and courses in order to get an adequate knowledge of effective instructional techniques to help EFL students engage in.

3- To possess an adequate knowledge of the rules and structural patterns of varied creative writing forms (e.g., poems, novels, and short stories).

4- To possess an adequate knowledge of various personally effective ways to meet the individual differences among students and help them translate accurately and write creatively.

5- To design and carry out the tasks and activities in an effective way to ensure that the students, especially demotivated ones, are actively participating.

6- To devote adequate time for instruction, group work and feedback.

\subsubsection{The Test on Participants' Creative Writing Skills.}

The following aspects were considered during the design of the test:

(i) Aim: to measure specific creative writing skills (fluency, flexibility, originality and problem sensitivity) among the firstlevel students of the English department at Port Said faculty of education. Data of the pre- and post- applications of the test were contrasted.

(ii) Resources: it was prepared with concern to varied resources, including

(1) the tests of creative writing skills proposed in previous related studies such as Akkaya (2014), Barbot, et al. (2012), Baig (2010), and Ming (2005). Additionally, a group of qualified responsible specialists including professors and assistant professors of TEFL, Translation, linguistics and Educational Psychology examined the test and submitted useful suggestions, comments and views. Furthermore, personal expertise helps the researcher prepare the sequence of the scale items in an adequate manner. In spite of the existence pf previous creative writing skills tests proposed in past studies, the researcher found it appropriate to develop a new test of creative writing skills for several reasons outside of control, 
Back Translation of Literary Texts and Its Effectiveness in Developing Creative Writing Skills and Academic Self-Efficacy among English Department First-level Students

Dr. Maged Mohammedain

including long time required to complete, variations of the target population, unclear instructions, inadequate sequence.

(iii) Intended creative writing skills: the test intended to measure the following:

$>$ Fluency: one's ability to come up with and write a number of ideas about a specific topic (the number of ideas is important, not their quality).

$>$ Flexibility: one's ability to generate or write a variety of ideas to specific problems in order to produce answers that make sense.

$>$ Originality: one's ability to come up with unusual ideas about a given topic.

$>$ Problem Sensitivity: one's ability to notice and recognize that others may notice and recognize.

(iv) The initial form of the test: Test specifications were prepared in the light of the analysis of the proposed unit based on the back translation strategy, relative weight in the subjects studied, and the intended creative writing skills. The test generally was composed of two parts: (i) participants' background information as well as an introduction to define its objectives, instructions, scoring method. (ii) the questions (items) designed to elicit creative writing skills of the participating sample. Originally, (12) test items were included in the initial form, distributed as follow: fluency (3 items), flexibility ( 3 items), originality ( 3 items), and problem sensitivity (3 items). The following considerations were taken into account:

$>$ all the sets of test item are correlated,

$>$ all items are relevant to the intended learning objectives,

$>$ All items are comprehensible and simple to the EFL students being tested.

In concern to the test instructions, they were considered to be brief, straight forward, easy to understand, simple, specific, carefully and precisely worded, clearly enough for all of the students and free from possible ambiguities.

(v) The Psychometric Properties of the Test:

Scoring: The maximum score was 60 marks. Four marks were given for each item.

Content validity: The test was submitted to a group of jury members including (8) professors and assistant professors of TEFL, Translation and Educational Psychology to examine the test items' quality, clarity, preciseness, sequence, suitableness, and potential to measure exactly and properly what is intended. The percentages of agreement among the jury members ranged $(89.9 \%-100 \%)$ on all the scale items, implying a relatively high validity for the test. All modifications proposed were made. 
Back Translation of Literary Texts and Its Effectiveness in Developing Creative Writing Skills and Academic Self-Efficacy among English Department First-level Students

Dr. Maged Mohammedain

The Test internal consistency: The table below provides a brief of the computed numerical values of the correlation coefficients between the scale's total score on one hand, and the score of each skill included in the scale on the other hand, had been calculated, ranging from $(0.69)$ to $(0.86)$. As shown in table (3.1), all the correlation coefficients were significant at ( $\alpha$ $\leq 0.01$ ) level, implying a relatively high internal consistency.

Table 3.1: Internal Consistency for the Scale

\begin{tabular}{|l|c|c|}
\hline $\begin{array}{l}\text { Creative } \\
\text { writing skills }\end{array}$ & $\begin{array}{l}\text { Total of } \\
\text { Items }\end{array}$ & $\begin{array}{l}\text { Correlation } \\
\text { Coefficients }\end{array}$ \\
\hline Fluency & $\mathbf{3}$ & $\mathbf{0 . 8 6}$ \\
\hline Flexibility & $\mathbf{3}$ & $\mathbf{0 . 7 8}$ \\
\hline Originality & $\mathbf{3}$ & $\mathbf{0 . 7 6}$ \\
\hline $\begin{array}{l}\text { Problem } \\
\text { Sensitivity }\end{array}$ & $\mathbf{3}$ & $\mathbf{0 . 6 9}$ \\
\hline
\end{tabular}

Items Difficulty \& Discrimination: the test was applied to a pilot sample including (48) student out of the main study sample. The computed correlation coefficients of items difficulty ranged from $\left(0.2^{\curlyvee}\right)$ to $(0.81)$. additionally, the computed correlation coefficients of items discrimination ranged from $(0 . r 3)$ to $(0 . \checkmark \wedge)$. These numerical values imply that the test is free of very difficult or very easy questions, and able to distinguish students of weak, moderate and strong levels in creative writing skills.

Test Time: Being applied to a pilot sample including (38) EFL first-level students out of the experimental group, (90) minutes was found as a suitable time for applying the test, in addition to other (5) minutes for reading the test instructions.

(vi) The final form of the test: Appendix (C) presents the final form of the test on participants' creative writing skills.

3.4.3. The Scale on Participants Academic Self-Efficacy in Translation.

The following aspects were considered during the design of the scale:

(i) Aim: it was to identify the development of EFL students' academic selfefficacy by virtue of the use of the proposed unit based on the back translation strategy. Data of the pre- and post- applications of the scale were contrasted.

(ii) Resources: varied resources had given way to the development of the scale on participants academic self-efficacy in translation, including such as Haro-Soler (2017), Way (2016), Bolaños-Medina (2014) and (2015), Lee (2014), Raoofi, et al., (2012), Atkinson (2012), Kargar \& Zamanian (2014), Muñoz (2014), Graham (2011), and Yilmaz (2010). Moreover, suggestions, recommendations, and pieces of advice on how to establish and prepare self-efficacy scales by a group of qualified education experts in TEFL, 
Back Translation of Literary Texts and Its Effectiveness in Developing Creative Writing Skills and Academic Self-Efficacy among English Department First-level Students

Dr. Maged Mohammedain

Translation and Educational Psychology were helpful. Additionally, the researcher's own expertise was valuable for revising, sequencing and improving the scale items.

(iii) The scale initial form: it was composed of two parts:

(1) participants' background information in which the enrolled participants are voluntarily providing personal data such as their names (optional), gender, age, and so forth. Also, a statement of the scale's objectives, instructions, and scoring method were clarified to enable the measurement of the progress of the enrolled participants. In regard to the scale instructions, they were considered to be specific, clearly expressed, straight forward, easy to understand, relevant, balanced, simple, and free from possible ambiguities.

(2) the scale items designed to elicit participants' academic self-efficacy in translation. The scale items were distributed as a 5-point Likert scale (Always / Very Often / Sometimes / Rarely / Never). The degrees assigned were (5 / 4 / 3 / 2 / 1) respectively. Initially, (29) items were included in the initial form of the scale. The minimum score was 29 marks. The maximum score was 145 marks. In regard to the scale items, following points were considered:

- able to be readily administered by the researcher.

- To provide clear directions to the enrolled participants to respond.

- measures what it intends to measure.

- Easiness of vocabulary and item's structure.

- To include appropriate items for measuring students' academic selfefficacy.

- To be scored in an objective and easy way.

- To allocate adequate time to answer and complete the scale.

The scale items were distributed into four main dimensions:

(i) Perceived control items: refer to one's belief that the process of learning creative writing is under his or her control.

(ii) Learning competence items: refer to one's belief about his or her own competence to perform a given task at a specific level.

(iii) Persistence items: refer to one's belief about his or her capacity to succeed in performing a particular task.

(iv) Self-regulated learning items: refer to one's belief about the factors of his or her successes or failures in a given task.

(iv) The Psychometric Properties of the Scale:

Face and content validity: (7) qualified professors and assistant professors of TEFL, Translation, Linguistics and Educational Psychology reviewed the scale in terms of clarity, sequence, and suitableness. Their modifications, and pieces of advice were considered. The percentages agreement among 
Back Translation of Literary Texts and Its Effectiveness in Developing Creative Writing Skills and Academic Self-Efficacy among English Department First-level Students

Dr. Maged Mohammedain

them implied a relatively high content validity as ranged between $(90.4 \%)$ and $(100 \%)$ on all items. However, they recommended to remove (8) items, considered repeated, inappropriate or not directly associated to the scale objectives, from the final form of the scale.

The Scale internal consistency: using Cronbach's alpha to examine the degree of correlation among the scale multiple items, all the computed numerical values of the correlation coefficients were significant at $(\alpha \leq 0.01)$ level, ranging from 0.65 to 0.76 , implying a relatively high internal consistency of the scale.

The Scale Reliability: using Cronbach's alpha, the computed numerical value for the scale reliability was $(\mathbf{0 . 8 4})$, showing the scale was reliable.

Test Time: in the pilot survey, (30) minutes was found as an appropriate time for applying the scale, in addition to other (5) minutes for reading the scale instructions.

(v) The final form of the scale: Appendix (D) presents a detailed description of the final form of the scale. It is consisted of (21) items, all of which were positives.

\subsection{Study Procedures}

This study was conducted in accordance with the following procedures:

I. Before starting the actual data collection process, it was necessary to carry out a pilot survey $(\mathrm{N}=38)$ to ensure validity, internal consistency, reliability of the instruments to ensure that their items are clearly articulated, relevant, straightforward and comprehensive.

II. The target sample was one group randomly selected and assigned as the experimental group $(\mathrm{N}=43)$, and treated with proposed unit based on the back translation strategy.

III. The test on participants' creative writing skills and the scale on participants' academic self-efficacy were pre-applied on the experimental groups. The mean scores, standard deviations and $T$. value in the pre- application of the instruments, were computed.

IV. The proposed unit based upon the back translation strategy included (10) sessions, administered for (5) weeks on the experimental group in the second semester of the academic year 2018 / 2019. Appendix (A) includes a detailed description of sequence of these sessions.

V. The test on participants' creative writing skills and the scale on participants' academic self-efficacy in translation were post-applied on the experimental groups. The mean scores, standard deviations and $T$. value of the experimental group were computed.

VI. An accurate and appropriate data analysis of the findings was carried out using SPSS.V22.0. in addition to Independent and Paired Samples T. Tests. 
Back Translation of Literary Texts and Its Effectiveness in Developing Creative Writing Skills and Academic Self-Efficacy among English Department First-level

Dr. Maged Mohammedain

\section{Findings and Conclusion}

This part discusses the study findings, significance, implications for EFL teaching practice, recommendations and suggestions for future research.

4.1 Findings and Discussions

The following findings of are outlined in accordance with the research hypotheses:

\subsubsection{Results related to the First Hypothesis:}

The first hypothesis states, "There is a statistically significant difference at $(\alpha \leq 0.01)$ between the mean scores of the experimental group students in the pre-application and post- application of the four dimensions of the creative writing skills test, in favor of the post applications". To verify such a hypothesis, the mean scores, standard deviations and $T$. value of the experimental group students in the pre-application and post- application of the creative writing skills test were computed using Paired T. Test, as shown in table (4.1).

Table (4.1): Mean scores, standard deviations and $T$. value of the experimental group students in the pre-application and post- application of creative writing skills test.

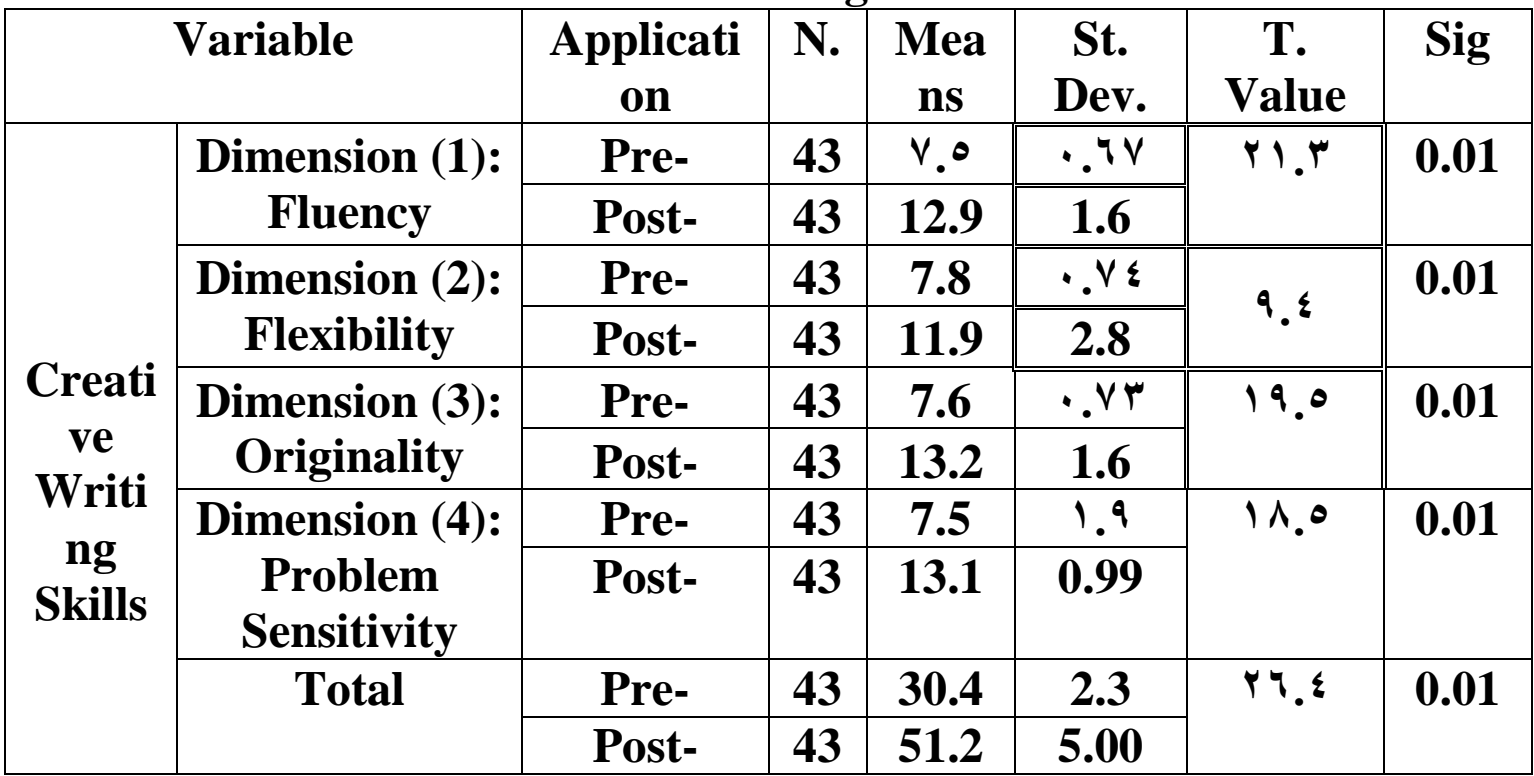

It is evident from the table above that the values of " $T$ " are statistically significant at the level of 0.01 , indicating a statistically significant difference between the mean scores of the experimental group students in the preapplication and post- application in the four dimensions of the creative writing skills test, and in the total score, in favor of the post applications. Figure (4.1) is a diagram of the aforementioned numerical values. 
Back Translation of Literary Texts and Its Effectiveness in Developing Creative Writing Skills and Academic Self-Efficacy among English Department First-level

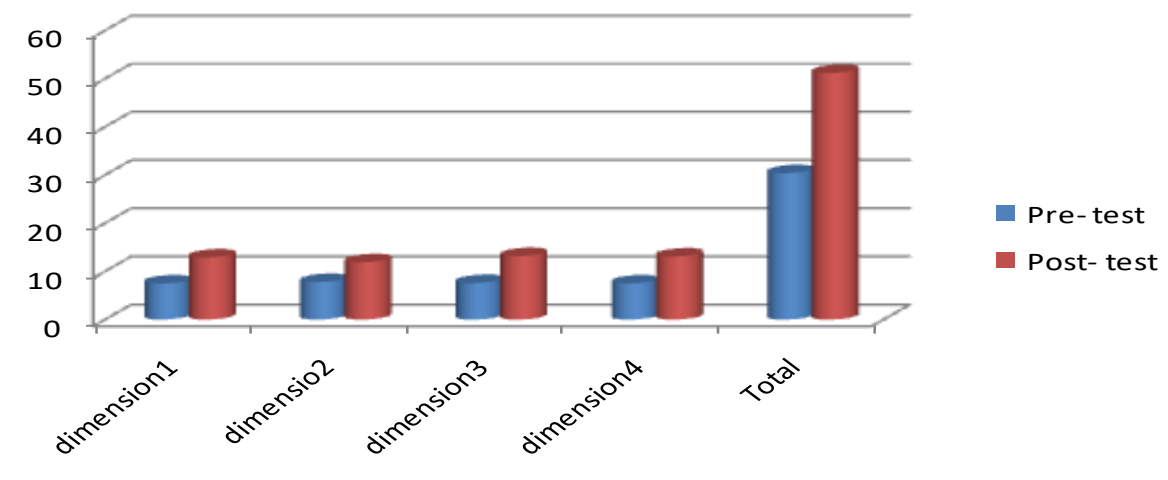

The above finding corroborates the findings of other research studies that investigated the issue of creativity in translation and writing and indicated the possible contribution of the back translation strategy as a tool for creative writing skills, including the findings of Behr (2017) and (2016), Bernadine (2016), Khanmohammad \& Kehtari (2015), Akkaya (2014), Abasi \& Shabani (2011), Gnecchi, et al. (2011), Antonietti, et al. (2011), Harkness, et al. (2009), Akbari (2007), and Aksoy (2001).These aforementioned studies shares a belief that translation is merely rewriting, and that EFL students can improve their writing skills if trained and guided adequately to translation practices.

A possible interpretation given to explain this finding might be that the back translation strategy has a significant role in enhancing the close connections between written and translated texts. Another interpretation of this finding might be that the including tasks, activities and learning experiences, as opposed to traditional ones, provided multiple opportunities for the participating sample to practice creative writing skills into deeper levels. A third possibility is that the proposed unit based on the back translation strategy was engaging, relevant, and giving the trainees good chances to organize their creative ideas in a logical and coherent manner. Added to this, its objectives and scope were clearly defined, and its periodic feedback during training was positive. These aspects urged the participating sample to be continually interested, focused during practicing the including tasks, activities.

\subsubsection{Results related to the Second Hypothesis:}

The second hypothesis states, "There is a statistically significant difference at $(\alpha \leq 0.01)$ between the mean scores of the experimental group students in the pre-application and post- application of the four dimensions of the academic self-efficacy scale, and in the total score, in favor of the post applications". To verify such a hypothesis, the mean scores, standard deviations and $T$. value of the experimental group students in the pre- 
Back Translation of Literary Texts and Its Effectiveness in Developing Creative Writing Skills and Academic Self-Efficacy among English Department First-level Students

Dr. Maged Mohammedain

application and post- application of the academic self-efficacy scale were computed, as shown in table (4.2).

Table (4.2): Mean scores, standard deviations and $T$. value of the experimental group students in the pre-application and post- application of academic self-efficacy scale.

\begin{tabular}{|c|c|c|c|c|c|c|c|}
\hline \multicolumn{2}{|c|}{ Variable } & $\begin{array}{l}\text { App } \\
\text { li. }\end{array}$ & N. & $\begin{array}{l}\text { Mea } \\
\text { ns }\end{array}$ & $\begin{array}{l}\text { St. } \\
\text { Dev. }\end{array}$ & T. Value & Sig. \\
\hline \multirow{10}{*}{$\begin{array}{l}\text { Academi } \\
\text { c Self- } \\
\text { Efficacy } \\
\text { Scale }\end{array}$} & \multirow{2}{*}{$\begin{array}{l}\text { Dimension (1): } \\
\text { Perceived Control }\end{array}$} & Pre- & 43 & 9.1 & .99 & \multirow{2}{*}{ Ir.r } & \multirow{2}{*}{$\begin{array}{c}0.0 \\
1\end{array}$} \\
\hline & & Post & 43 & 12.8 & 1.70 & & \\
\hline & \multirow{2}{*}{$\begin{array}{l}\text { Dimension } \\
\text { Competence }\end{array}$} & Pre- & 43 & 7.7 & $1 . \wedge \mathbf{0}$ & \multirow[b]{2}{*}{11.00} & \multirow{2}{*}{$\begin{array}{c}0.0 \\
1\end{array}$} \\
\hline & & $\begin{array}{l}\text { Post } \\
-\end{array}$ & 43 & 12.7 & r.ro & & \\
\hline & \multirow{2}{*}{$\begin{array}{l}\text { Dimension } \\
\text { Persistence }\end{array}$} & Pre- & 43 & 6.9 & 1.70 & \multirow{2}{*}{17.7} & \multirow{2}{*}{$\begin{array}{c}0.0 \\
1\end{array}$} \\
\hline & & $\begin{array}{l}\text { Post } \\
-\end{array}$ & 43 & 13.3 & 1.90 & & \\
\hline & \multirow{2}{*}{$\begin{array}{l}\text { Dimension (4): } \\
\text { Self- Regulated } \\
\text { Learning }\end{array}$} & Pre- & 43 & 7.6 & $1 . \leqslant 0$ & \multirow[t]{2}{*}{$1 V .1$} & \multirow{2}{*}{$\begin{array}{c}0.0 \\
1\end{array}$} \\
\hline & & $\begin{array}{l}\text { Post } \\
-\end{array}$ & 43 & 13.2 & 1.70 & & \\
\hline & \multirow[t]{2}{*}{ Total } & Pre- & 43 & 31.3 & T.ro & \multirow[t]{2}{*}{ Y^.\& } & \multirow{2}{*}{$\begin{array}{c}0.0 \\
1\end{array}$} \\
\hline & & $\begin{array}{l}\text { Post } \\
\text { - }\end{array}$ & 43 & 52.1 & $\{.10$ & & \\
\hline
\end{tabular}

It is evident from the table above that the significant difference of the in the pre-application and post- application in the four dimensions of the academic self-efficacy scale was in favor of the post-application in which the mean score of the post- academic self-efficacy scale was 52.1, while the mean score of the pre- academic self-efficacy scale was 31.30. Figure (4.2) is a diagram of the aforementioned numerical values.

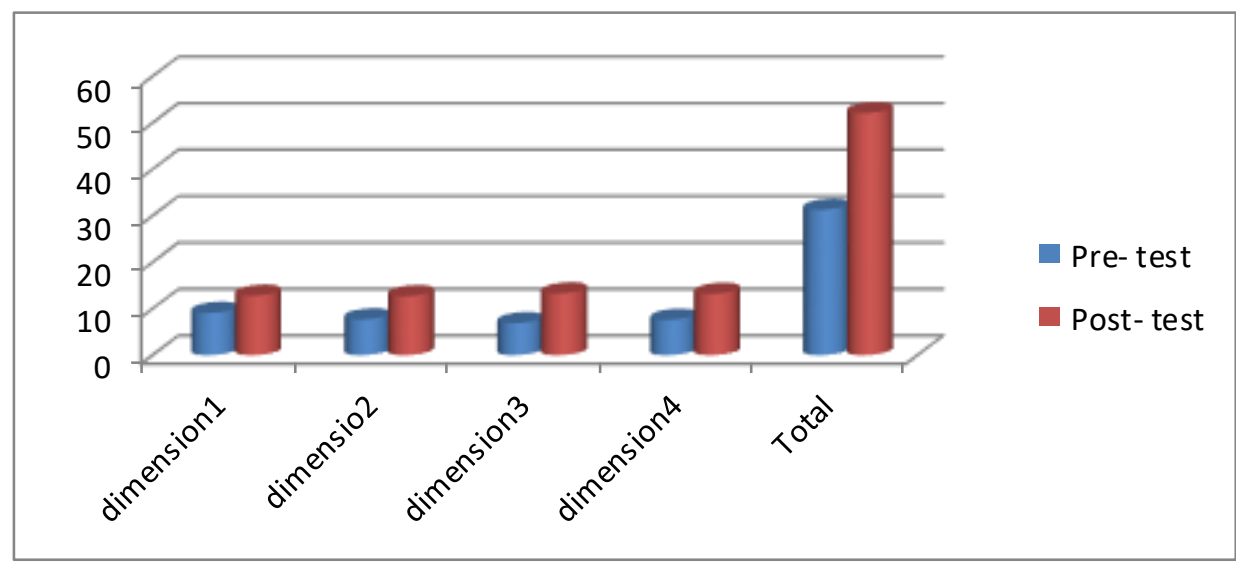


Back Translation of Literary Texts and Its Effectiveness in Developing Creative Writing Skills and Academic Self-Efficacy among English Department First-level Students

Dr. Maged Mohammedain

The above finding corroborates the findings of other research studies that investigated the issue of creativity in translation and writing and indicated that success in translation tasks could be a positive predictor of students' academic performance, including the findings of Haro-Soler (2017), Way (2016), Bolaños-Medina (2015), Atkinson (2012), Muñoz (2014). These aforementioned studies recognized that translation as an instrument can develop translators' specific self-efficacy beliefs, influence their performance, increase their enrollment of EFL lessons, and improve their sense of expertise.

A possible interpretation of this finding might be that the proposed unit has included authentic materials that facilitated class interactions and communication. Additionally, the included tasks planned to increase writing accuracy and relevancy, problem-solving activities, frequent quizzes, and step-by-step feedback encouraged deeper learning and understanding of the participating sample, leading them to feel more in control of their own learning. A third possible interpretation of this finding might be that the proposed unit has emphasized an individual's interest to complete translation tasks, resulting in greater confidence and self-efficacy.

\subsection{Implications}

A main objective of the present study was to address the lack of empirical studies in Egypt on the back translation strategy, creative writing skills and academic self-efficacy of translators. This objective has been attained through a controlled well-constructed and well-conducted study with special attention to the instruments' validity, internal consistency and reliability. Accordingly, the first implication this study is to consider the significance of translation use in the context of EFL instruction, and for the development of skills and knowledge among EFL students. This calls education policy makers at the university level to redesign the EFL curricula accordingly. A second important implication is to consider new and unique strategies for the development of creative writing skills in the EFL learning environment. This calls EFL teachers to look at effective means to help EFL students unleash their creativeness. Along with creative writing, EFL teachers should adopt strategies to help EFL students develop their academic self-efficacy for its significance in increasing students' progress, achieving their goals, and meeting varied challenges in the EFL environment.

\subsection{Delimitation:}

As a matter of fact, every study involves delimitations. Though wellconstructed and conducted, possible delimitations of the present study, that were out of the researcher's control, were restricted. The number of participants contributed was limited $(\mathrm{N}=43)$. It would become better to involve a larger number in order to make generalizations for the whole 
Back Translation of Literary Texts and Its Effectiveness in Developing Creative Writing Skills and Academic Self-Efficacy among English Department First-level Students

Dr. Maged Mohammedain

EFL students. Still, because of limited time, the participating sample utilized in this research was a group of the first-level students of the English Department at Port Said faculty of education. It would become better to investigate other EFL students enrolling at other Egyptian faculties of education.

\subsection{Conclusion}

Despite the utmost significance of translation use in the pedagogy of EFL teaching and learning, it has been frequently ignored. This study is an effort to restore the significant role of translation as a proper and essential, tool of EFL language teaching. The back translation strategy was used in the present study for the development, practice and improvement of creative writing skills, which are necessary skills for EFL students' academic success, and for the development and improvement of academic selfefficacy, which is significant in overcoming negative factors that hinder EFL development such as, anxiety, fear of failure, and unwillingness to write. Through an enjoyable and supportive EFL unit of exciting translation tasks and activities, the creative writing skills and academic selfefficacy of the first-level students enrolled in the English department at Port Said Faculty of Education were fostered and enhanced after the back translation strategy was used as an instructional technique. The type of the present research provides EFL curricula developers, researchers teachers, and students a deeper insight into the creative process and the significant role of translation use in teaching English as foreign language for offering plentiful opportunities for personal and educational development. Hence, it can be suggested that the back translation strategy integrated into the syllabus of English language in general, and in the writing courses in special.

\subsection{Suggestions for Further Research}

On the basis of the findings of this study, the following studies are suggested:

- Conducting the same research in other EFL contexts.

- To investigate the impact of other strategies on developing academic self-efficacy.

- To investigate the impact of back translation on the development of reading.

- To apply the same research instruments with a larger EFL sample.

\subsection{Recommendations}

Based on of the above findings, the following recommendations may be useful:

- To make training courses in translation available on a regular basis to help EFL students achieve competence in the foreign language. 
Back Translation of Literary Texts and Its Effectiveness in Developing Creative Writing Skills and Academic Self-Efficacy among English Department First-level Students Dr. Maged Mohammedain

- To make training courses in creative writing available. Without these skills, a text may be structured wrongly and can cause the target reader to misunderstand it.

- To urge EFL teachers to develop the creative writing of their students using varied texts such as novels, poetry, and short story collections.

- To urge EFL teachers to use specific learning strategies that can develop the academic self-efficacy of their students and allow make their own choices. 
Back Translation of Literary Texts and Its Effectiveness in Developing Creative Writing Skills and Academic Self-Efficacy among English Department First-level Students

Dr. Maged Mohammedain

\section{References}

Abasi, Sh., \& Shabani, Gh. (2011). The effect of proficiency in writing on EFL students' translation. International Conference on Languages, Literature and Linguistics, 26, 521-525.

Akbari Pakdaman, H. (2007). The relationship between English writing ability and Persian- English translation ability among translation trainees. (Unpublished master's thesis). Science and Research Branch of Islamic Azad University, Tehran, Iran.

Akkaya, N. (2014). Elementary Teachers' Views on the Creative Writing Process: An Evaluation. Educational Sciences: Theory and Practice, 14(4), 1499-1504.

Anae, N. (2014). Creative writing as freedom, education as exploration: Creative writing as literary and visual arts pedagogy in the firstyear teacher-education experience. Australian Journal of Teacher Education,39(8), 123-142.

Aksoy, Berrin. (2001). Translation as a rewriting: the concept and its implications on the emergence of a national literature. Translation Journal. (5): 3

Al-Quyad, A. (2014). The teaching of translation at the university level: Constraints and aspirations. Arab World English Journal, 5(2), 133-141.

Atkinson, D. P. (2012). Freelance translator success and psychological skill: A study of translator competence with perspectives from work psychology. Unpublished doctoral thesis, University of Auckland, New Zealand.

Baker, M. (2002). In other words: A course book on translation. Beijing: Foreign Language Teaching and Research Press.

Bandura, A. (1977). Self-efficacy: Toward a unifying theory of behavioral change. Psychological Review, 84, 191-215

Bandura, A. (1993). Perceived self-efficacy in cognitive development and functioning. Educational Psychologist, 28, 117-148.

Baptiste Barbot a, Mei Tan a, Judi Randi b, Gabrielle Santa-Donato c, Elena L. Grigorenko. (2012). Essential skills for creative writing: Integrating multiple domain-specific perspectives. Thinking Skills and Creativity, 7: 209-223.

Bassnett, S. (2004). Translation Studies. London/New York: Routledge.

Behr, D. (2016). Assessing the use of back translation: The shortcomings of back translation as a quality testing method. International Journal of Social Research Methodology, 20:6, 573-584.

Behr, D. (2017). Assessing the use of back translation: The shortcomings of back translation as a quality testing method. International Journal of Social Research Methodology, 20:6, 573-584. 
Back Translation of Literary Texts and Its Effectiveness in Developing Creative Writing Skills and Academic Self-Efficacy among English Department First-level Students

Dr. Maged Mohammedain

Bennett, A., Clarke, G., Motion, A., \& Naidoo, B. (2008). Creative writing subject benchmark statement. Retrieved on 19 / 10 / 2019 from http://www.nawe.co.uk/writing-in-education/writing-atuniversity/research.html

Bernadine, R. (2016). What is Back Translation and Why is it Necessary. Retrieved from: https://www.daytranslations.com/blog/what-isback-translation/ (accessed on 24 feb, 2018|)

Boase-Beier, J., \& Holman, M. (2007). The practices of literary translation. Constraints and creativity. Manchester: St. Jerome.

Bolaños-Medina, A. (2014). Self-Efficacy in Translation. Translation and Interpreting Studies, 9, 2, 197-218.

Brockbank, Eileen. (2001). The translator is a writer. Translation Journal. (5):2

Chen, S., \& Zhou, J. (2010). Creative writing strategies of young children: Evidence from a study of Chinese emergent writing. Thinking Skills and Creativity, 5(3), 138-149.

Chesterman, Andrew. (2009). The Name and Nature of Translator Studies. Hermes Journal of Language and Communication Studies 42: 13-22.

Cho, Sang-Eun (2006). Translator's Creativity Found in the Process of Japanese-Korean Translation. Meta, 51 (2): 378-388.

Colina, S., Marrone, N., Ingram, M., \& Sánchez, D. (2016). Translation quality assessment in health research: A functionalist alternative to back-translation. Evaluation \& the Health Professions. Advance online publication. https://doi.org/10.1177/0163278716648191

Cook, G. (2010). Translation in language teaching. Oxford and New York: Oxford University Press.

Cremin, T. (2006). Creativity, uncertainty and discomfort: Teachers as writers. Cambridge Journal of Education, 36(3), 415-433

Dam-Jensen, H., \& Heine, C. (2013). Writing and translation process research: Bridging the gap (Introduction). Journal of Writing Research, 5(1), 89-101.

DeTure, M. (2004). Cognitive style and self-efficacy: predicting student success in online distance learning. The American Journal of Distance Education, 18(1), 21-38.

Douglas, S. P., \& Craig, C. S. (2007). Collaborative and iterative translation: An alternative approach to back translation. Journal of International Marketing, 15(1), 30-43.

Dündar, Ş. (2015). Are prospective elementary school teachers' social studies teaching efficacy beliefs related to their learning 
Back Translation of Literary Texts and Its Effectiveness in Developing Creative Writing Skills and Academic Self-Efficacy among English Department First-level

Dr. Maged Mohammedain

approaches in a social studies teaching methods course? Australian Journal of Teacher Education, 40(7), 70-85.

Everett, N. (2005). Creative Writing and English._The Cambridge Quarterly, 34, (3), 231-242.

Genç, G., Kuluşaklı, E., \& Aydın, S. (2016). Exploring EFL Learners' Perceived Self-efficacy and Beliefs on English Language Learning. Australian Journal of Teacher Education, 41(2).

Ghaiyoomian, H., \& Zarei, Gh. (2015). The effect of using translation on learning grammatical structures: A case study of Iranian high school students. Research in English Language Teaching, 3 (1), 32-39.

Gile, D. (2009). Basic concepts and models for interpreter and translator training. Amsterdam: John Benjamins.

Gnecchi, M., Maylath, B., Mousten, B., Scarpa, F., \& Vandepitte, S. (2011). Field convergence between technical writers and technical translators: Consequences for training institutions. IEEE Transactions on Professional Communication, 54(2), 168-184.

Graham, S. (2011). Self-efficacy and academic listening. Journal of English for Academic Purposes, 10 (2), 113-117.

Harkness, J., Villar, A., Kephart, K., Behr, D., \& Schoua-Glusberg, A. (2009). Research on translation assessment procedures: Back translation and expert review. Paper presented at the International Workshop on Comparative Survey Design and Implementation. Ann Arbor, MI.

Harmer, J. (2004). How to teach writing. Malaysia: Pearson Education Limited.

Haro-Soler, M. M. (2017). Teaching Practices and Translation Students' Self-Efficacy: A Qualitative Study of Teachers' Perceptions. Current Trends in Translation Teaching and Learning E, 4, 198228.

HE, X. B. (2002). The types, features and methods of back-translation. Chinese Technical Translation, 4, 45-54.

Honda, Mineko. (2011). Creative Writing in Pairs: Pedagogic Possibilities in Japanese University EFL Classes. Komaba Journal of English Education, (2): 45-63.

Hosseini Fatemi, A., \& Vahidnia, F. (2013). An investigation into Iranian EFL learners' level of writing self-efficacy. Theory and Practice in Language Studies, 3(9), 1698-1704.

Hyland, K. (2003). Second language writing. NY: Cambridge University Press.

Kargar, M., \& Zamanian, M. (2014). The relationship between self-efficacy and reading comprehension strategies used by Iranian male and 
Back Translation of Literary Texts and Its Effectiveness in Developing Creative Writing Skills and Academic Self-Efficacy among English Department First-level

Dr. Maged Mohammedain

female EFL learners. International Journal of Language Learning and Applied Linguistics World, 7(2), 313-325.

Karimian, Z., \& Talebinejad, M. R. (2013). Students' use of translation as a strategy in EFL classroom. Journal of Language Teaching and Research, 4(3), 605- 610.

Khanmohammad, H. \& Kehtari, M. (2015). Relationship between writing with translation from native to foreign, and reading with translation from foreign to native languages. ELT Voices, 5(4), 29-45.

Khosravani, Y. \& Vahid Dastjerdi, H. (2013). Back Translation vs. Collaborative Translation: A Comparative Study of Persian Subtitles in English Movies. Lebende Sprachen; 58(2): 366-378

Lee, S. B. 2014. An Interpreting Self-efficacy (ISE) Scale for Undergraduate Students Majoring in Consecutive Interpreting: Construction and Preliminary Validation. The Interpreter and Translator Trainer 8 (2) 183-203.

Leonardi, V. (2011). Pedagogical translation as a naturally occurring cognitive and linguistic activity in foreign language learning. Annali Online di Lettere-Ferrara, 2, 17-28.

Loffredo, E., \& Perteghella, M. (2006). Translation and creativity. Perspectives on creative writing and translation studies. London: Continuum.

Liu, M. (2013). English bar as a venue to boost students' speaking selfefficacy at the tertiary level. English Language Teaching, 6(12), 22-37.

Machida S (2011). Translation in teaching a foreign (second) language: A methodological perspective. Journal of Language Teaching and Research, 2 (4),740-746

Mahboob, A., \& Elyas, T. (2014). English in the Kingdom of Saudi Arabia. World Englishes, 33(1), 128-142.

Maley, A. (2009). Creative writing for language learners. Retrieved on 18 April 2018 from: http://www.teachingenglish.org.uk/article/creative-writinglanguagelearners-teachers

Maley, A. (2012). Creative Writing for Students and Teachers. Humanizing Language Teaching,

14(3). Retrieved on 18 April 2019 from http://www.hltmag.co.uk/jun12/mart01.htm

Ming, C. (2005). Describing and enhancing creativity in Chinese writing. (Doctoral dissertation). Hong Kong: University of Hong Kong.

Mogahed, M. (2011). To use or not to use translation in language teaching. Translation Journal, 15(4), 2-4. 
Back Translation of Literary Texts and Its Effectiveness in Developing Creative Writing Skills and Academic Self-Efficacy among English Department First-level Students

Dr. Maged Mohammedain

Morley, D. (2007). Introduction to Creative Writing. Cambridge: Cambridge University Press.

Muñoz Martín, R. (2014). Situating Translation Expertise: A Review with a Sketch of a Construct. In J. W. Schwieter and A. Ferreira (Eds.), The Development of Translation Competence: Theories and Methodologies from Psycholinguistics and Cognitive Science, (pp. 2-57). Newcastle: Cambridge Scholars Publishing.

Neupane, S. (2014). Issues and Challenges of Teaching Creative Writing. ELT CHOUTARI, 80(5), 340-344

O'Brien, S. (2013). The borrowers: Researching the cognitive aspects of translation. Target, 25(1), 5-17.

Ozolins, U. (2009). Back translation as a means of giving translators a voice. Translation \& Interpreting, 1(2), 1-13.

Paegelow, R. S. (2008). Back Translation Revisited: Differences that Matter (and Those that Do Not). The ATA Chronicle, 1, 22-25.

Perteghella, M. \& Loffredo, E .(2007). Translation and creativity. London: Continuum, p. 1-16.

Prasteyo, D. (2016). The correlation between translation ability and reading habit toward writing ability. Published M.A. thesis, ISLAMIC EDUCATION AND TEACHING TRAINING FACULTY, THE STATE ISLAMIC INSTITUTE OF SURAKARTA

Racoma, B. (2016). What is Back Translation and Why is it Necessary?. Retrieved on 17 / 10 / 2018 from: https://www.daytranslations.com/blog/what-is-back-translation/

Rahemi, E. F., Jufri, M., \& Havid Ardi, S. (2013). The correlation between reading comprehension and translation ability: A correlational study on fourth year students at English Department of UNP. Journal of English Language Teaching, 1(2), 178-186.

Raoofi, S., Hoon Tan, B., \& Heng Chan, S. (2012). Self-efficacy in second/foreign language learning contexts. English Language Teaching, 5(11), 60-73.

Runco, M. A. (2009). Writing as an interaction with ideas. In S. B. Kaufman, \& J. C. Kaufman (Eds.), The psychology of creative writing (pp. 180-195). New York: Cambridge University Press

Shanahan, T. (2006). Relations among oral language, reading, and writing development. In C. A. MacArthur, S. Graham, \& J. Fitzgerald (Eds.), Handbook of writing research (pp. 171-183). New York: Guilford Press.

Sharma \& Nasa, G. (2014). Academic self-efficacy: a reliable predictor of educational performances. British Journal of Education, 2 (3), 57-64

Spiro, J. (2004). Creative Poetry Writing. Oxford: Oxford University Press. 
Back Translation of Literary Texts and Its Effectiveness in Developing Creative Writing Skills and Academic Self-Efficacy among English Department First-level Students Dr. Maged Mohammedain

Sternberg, R. J., Kaufman, S. B., \& Kaufman, J. C. (2009). Foreword. In The psychology of creative writing. New York, NY: Cambridge University Press. (pp. xv-xvii).

Tyupa, S. (2011). A Theoretical Framework for Back-Translation as a Quality Assessment Tool. New Voices in Translation Studies, (7),35-46

Vu Cong Duy Hoang, Philipp Koehn, Gholamreza Haffari, and Trevor Cohn. (2018). Iterative back-translation for neural machine translation. ACL, 1

Wang, Q. (2009). Application of back-translation to improve students' English language competence). Ningbo University Journal, 4, 130-133.

Warren, A. (2013). 10 creative ways to teach English that deliver outstanding results. Retrieved on 18 April 2019 from http://www.theguardian.com/teachernetwork/teacherblog/2013/feb/14/teaching-english-creatively-outstandingresults

Way, C. (2016). The Challenges and Opportunities of Legal Translation and Translator Training in the 21st Century. International Journal of Communication, 10, 1009-1029.

Yilmaz, C. (2010). The relationship between language learning strategies, gender, proficiency and self-efficacy beliefs: A study of ELT learners in Turkey. Procedia - Social and Behavioral Sciences, 2(2), 682-687.

Zawawy, A. (2008). Pining down creativity in translation: the case of literary texts. Translation Directory. Retrieved on 10 / 3 / 201^, from http://www.translationdirectory.com/article1750

Zhao, Y. (2015). Using translation in ESL classrooms: An Asian perspective. International Journal of Innovative Interdisciplinary Research, 14, 83-51. 